\title{
A ATUAÇÃO SINDICAL PROFISSIONAL: REPERCUSSÕES DA REFORMA TRABALHISTA E MEDIDAS EMERGÊNCIAIS EM VIRTUDE DA PANDEMIA
}

\author{
Karoline Rodrigues de Souza* \\ Elaine Cristina Saraiva Bentivoglio**
}

\section{RESUMO}

Após dois anos da Lei 13.467/2017, conhecida como "reforma trabalhista", entrar em vigor, o futuro das entidades sindicais permanece incerto e os impactos começam a ser notados em um momento de pandemia, o que tornou necessária a adoção de medidas emergenciais para regulamentar as relações de trabalho nesta situação excepcional. Percebe-se que o trabalho é algo essencial na vida do ser humano, pois está ligado à dignidade da pessoa, seus anseios e conquistas. O objetivo deste trabalho é verificar se as alterações decorrentes das novas leis proporcionarão proteção e amparo ao trabalhador, mantendo a representação coletiva na relação de trabalho. Assim, servirá de base para este estudo averiguar por meio de pesquisa bibliográfica o desenvolvimento histórico dos sindicatos, a forma que a sua atuação está prevista na legislação vigente, a importância da proteção de direitos comuns e a necessidade de mecanismos que regulem a relação dos trabalhadores como um todo.

Palavras-chave: Reforma trabalhista. Pandemia. Trabalhador. Medidas emergenciais. Representação. Sindicatos.

\section{PROFESSIONAL TRADE UNION: LABOR REFORM REPERCUSSIONS AND EMERGENCY MEASURES IN VIRTUE OF THE PANDEMIC}

\section{ABSTRACT}

After two years of the Law 13.467 / 2017, commonly known as "labor reform", come into force, the union entities future remains uncertain and the impacts are beginning to be noticed in the pandemic moment, which made it necessary to adopt emergency measures to regulate labor relations in such exceptional situation. It is perceived that work is something essential in the human being life, as it is linked to the person's dignity, their desires and achievements. The objective of this work is to verify if the changes resulting from the new laws will provide protection and support to the worker, maintaining collective representation in the employment relationship. Thus, it will serve as a basis for this study to investigate through bibliographic research the unions historical development, the way in which their performance is predic-

* Advogada. Pós-graduanda em Direito e Processo do Trabalho pela Faculdade Damásio Educacional.

** Advogada. Professora universitária. Mestre em Direito. 
ted in the current legislation, the importance of protecting common rights and the need for mechanisms to regulate the workers' relationship as a whole.the current legislation, the importance of protecting common rights and the need for mechanisms to regulate the workers' relationship as a whole..

Keywords: Labor reform.Pandemic.Worker.Emergency measures.Representation. Unions.

\section{INTRODUÇÃO}

Os sindicatos se tornaram instrumento imprescindível para a organização da classe trabalhadora e para a busca por uma sociedade mais justa e democrática, na tentativa contínua de ampliar direitos.

Nos termos do artigo $8^{\circ}$, inciso III da Constituição Federal de 1988, o sindicato tem o dever de defender os direitos e interesses coletivos e individuais da categoria, inclusive, em questões judiciais ou administrativas.

A Lei 13.467/2017, conhecida como Reforma Trabalhista, trouxe mudanças expressivas no tocante à perspectiva do direito coletivo, motivo pelo qual se faz necessária uma análise específica para verificar se tal alteração legislativa causou impactos nas funções supramencionadas, bem como, se as organizações de classe terão a capacidade e o amparo legal necessário para defender a categoria profissional.

E ainda, a pandemia de 2020, causada pela Covid-19, causou grande abalo na economia mundial, e consequentemente nas relações de trabalho. Em um momento excepcional como este, torna-se ainda mais indispensável a participação dos sindicatos na vida dos trabalhadores.

O presente trabalho visa examinar por meio de análise bibliográfica, a importância da atuação sindical profissional no que concerne à proteção do trabalhador, no sentido de que esse, como parte estruturalmente mais fraca na relação de trabalho, tenha chances de sucesso nos processos negociais. Para isso, existe o axioma de que suas entidades representativas precisam dispor de recursos, políticos e financeiros, para refutar as corporações empresariais, tornando cabível a análise da lei e das medidas emergenciais adotadas, para averiguar se elas fornecem os elementos necessários para proporcionar condições viáveis de luta e se está em harmonia com os institutos previstos na carta magna vigente.

\section{O TRABALHO COMO PARTE DA HISTÓRIA HUMANA}

O trabalho é algo necessário na vida de todos os seres humanos e pode trazer variações em seu significado para cada indivíduo.

Trata-se do principal núcleo da vida de homens e mulheres, não havendo ambiente mais propício para o desenvolvimento da autonomia coletiva. (MENDES, 2018, p. 59).

Por intermédio do trabalho, foi dado aos indivíduos um conhecimento mais preciso do funcionamento da política e da sociedade, com o consequente aumento da autonomia coletiva. (MIGUEL, 2014, p. 64).

Observa-se que o trabalho constitui a base para o desenvolvimento da sociedade e sobrevivência humana. 
Desta forma, pode-se verificar que o sentido e a forma de trabalho agregam mudanças ao longo do período histórico da humanidade, e por intermédio desse fato cria-se e transforma-se o direito, que se inicia do coletivo para o individual, nesse sentido:

\begin{abstract}
Na medida em que o processo econômico, no interior do qual se desenvolvem estas relações, é um fenômeno coletivo, comunitário, o modelo de relação de trabalho que melhor harmonize com o processo econômico tende a ser generalizado. (CASSAR, 2018, p.255).
\end{abstract}

O trabalho de maneira ampla abrange as atividades que o homem realiza em cooperação com outros, sendo o sindicato o espaço onde essa contribuição pode se manifestar. (MENDES, 2018).

As relações jurídicas estão dentro de um processo que se desenvolve de maneira a globalizar todo o coletivo, a partir de um fato de repercussão geral, para o caso concreto de cada um.

\title{
PRINCÍPIOS NORTEADORES DO DIREITO COLETIVO DO TRABALHO
}

A nossa Carta Magna possui, na sua estrutura, princípios que devem permear todas as áreas. Deste modo, o trabalho deve preencher os valores sociais e os objetivos fundamentais na construção de uma sociedade livre, justa e solidária para, por meio dele, alcançar o desenvolvimento nacional e a erradicação da pobreza, tendo sempre a finalidade de propiciar o bem de todos, sem preconceitos ou discriminações.

A palavra "princípio" significa preceito, origem ou regras, os quais estão presentes em todo ordenamento jurídico e, nem sempre, de modo escrito. (GUIMARÃES, 2016). Porém, deve-se enfatizar que os princípios têm vida própria, independentemente de estarem explicitamente descritos no Direito Positivo. (SANTOS, 2019).

O direito tem, em sua estrutura basilar, princípios que expressam valores culturais e os grandes anseios da sociedade. Eles funcionam como linhas mestras que orientam o caminho a ser seguido para a criação e interpretação das leis:

\footnotetext{
Tomado o direito positivo como camada de linguagem prescritiva que se projeta sobre a região material das condutas intersubjetivas para discipliná-las e orientá-las na direção de certos valores que a sociedade quer ver implantados, ele, direito posto aparece como a construção do ser humano.(CARVALHO, 2011. p.[4]).
}

Os princípios são premissas implantadas por valores históricos e sociais adquiridos por um grupo de pessoas vividas no mesmo tempo e região, que possuem interesses basilares em comum que devem ser respeitados para a construção de uma vida em sociedade harmoniosa, demonstrando um rumo a ser seguido que se sobressai às diferenças naturais que cada indivíduo, em sua singularidade, tem 
em relação ao outro, sejam essas alteridades políticas ou religiosas, para que assim, haja a inserção de um ordenamento jurídico em um dado país.

Nessa linha de raciocínio, o já mencionado professor Paulo de Barros Carvalho (2011) aponta que todo princípio atua para implantar valores.

Considera-se que na estrutura normativa, os princípios encontram-se em posição de destaque e prevalência sobre as demais regras.

Para aplicação e criação das leis infraconstitucionais, cuja matéria dispõe sobre o direito coletivo do trabalho, é de extrema relevância a observação dos princípios da liberdade associativa e sindical, da inalterabilidade contratual lesiva, da intervenção obrigatória sindical, da equivalência entre os negociantes, da preponderância do interesse coletivo sobre o individual, da criatividade jurídica na negociação coletiva, da adequação setorial negociada, da razoabilidade e da proteção.

Quanto ao princípio da proteção, cabe ressaltar que este alude ao fato do direito do trabalho, de maneira ampla, destacar-se pela sua função tutelar, dada a condição de vulnerabilidade do trabalhador mediante a superioridade econômica do empregador. Trata-se de um direito de cunho originalmente reivindicatório e intervencionista.

\section{O SURGIMENTO E A EVOLUÇÃO DO SINDICALISMO}

Para analisar as recentes alterações jurídicas no direito coletivo do trabalho, convém discorrer sobre os fatores sociais, que de forma involuntária, tornaram necessária a criação de uma entidade com o viés de defender os interesses coletivos dos trabalhadores para, assim, visualizar com clareza os desafios trazidos pela reforma implantada em 2017, e o impacto da pandemia causada pelo Coronavírus no mundo do trabalho.

Segundo o Dicionário Técnico Jurídico (2016), o sindicalismo refere-se ao movimento que preconiza a organização das categorias profissionais de todos os trabalhadores, na figura dos sindicatos, federações e confederações.

Um importante marco para o início da construção do direito coletivo do trabalho ocorreu no período das revoluções Francesa e Industrial, marcadas pelo surgimento das máquinas a vapor, no final do século XVIII, estabelecendo o nascimento do trabalho subordinado. Algo que perfez com que houvesse uma demanda desenfreada de trabalho com jornadas excessivas, salários injustos, exploração de menores e mulheres; ficando marcada pela ausência de proteção aos trabalhadores com a consequência de inúmeros acidentes de trabalho. (SANTOS, 2019).

Os fatos narrados foram relatados no filme Tempos Modernos (1936), de Charlie Chaplin, que demonstra a passagem da produção artesanal para a produção em larga escala, sendo esta forma de trabalho considerada desumana. Esse trabalho não condiz com as condições físicas e psicológicas dos trabalhadores, por visar unicamente a obtenção do maior lucro possível para os empregadores, ficando caracterizada uma relação de exploração que retratava as dificuldades que a sociedade vivia na época. Tal tipo de labor afeta diretamente na saúde e qualidade de vida. 
Em 1850, nascia o tradeunismo que, traduzido para o português, significa sindicato. Ficou historicamente conhecido por ser o movimento sindical inglês mais antigo do mundo e por ter promovido a Trade Union Congress, central sindical que reuniu os sindicados por profissão e por indústria, surgindo nessa época os primeiros instrumentos coletivos dispondo sobre direitos, denominados gentlemen'sagreement, que significa "acordo de cavalheiros". (NASCIMENTO, 2013).

A Igreja Católica também teve seu papel na construção dos direitos trabalhistas. Quando o Papa Leão XIII escreveu a encíclica Rerum Novarum, de 1891, argumentando sobre a necessidade da organização sindical, para que ambas as partes fossem cientes de seus direitos e deveres, evitando abusos e excessos, devendo prevalecer entre essas duas classes distintas a concórdia e a harmonia, por intermédio de homens, que em reunião, compartilhassem ideias, unissem forças e se organizassem para realizar ações conjuntas, e ter como resultado um trabalho digno, honroso e proveitoso (CORTELLA, 2017).

Em suma, a encíclica preceitua que seria fundamental que o Estado protegesse essa organização, segundo o direito, mas que não se intrometesse no seu governo interior.

Cabe mencionar, neste estudo, o entendimento propagado por Karl Marx e Engels, na obra "Manifesto Comunista", de 1848, que considerava necessária uma revolução operária para que os trabalhadores fossem a classe dominante dentro do sistema democrático, convocando os operários a se unirem. (SANTOS, 2019).

Marx e Engels (1848) apontavam que, ao longo da história da humanidade, sempre existiu a luta entre classes: homem livre e escravo, patrício e plebeu, senhor feudal e servo, mestre de corporação e companheiro, opressores e oprimidos, em uma constante oposição.

Eles concluíram que, em virtude das crises comerciais, os trabalhadores sempre acabavam reféns de salários instáveis, enquanto os proprietários buscavam cada vez mais o aperfeiçoamento das máquinas, intensificando as precárias condições de trabalho.

No cenário mundial, as primeiras constituições que trataram dos direitos trabalhistas, como algo fundamental para o desenvolvimento social, foram a do México, em 1917, e a Alemã, de Weimar, em 1919, que foi a primeira a tratar do direito de associação. (NASCIMENTO, 2013).

No decorrer do século, a Organização Internacional do Trabalho implantou diversas normas de proteção da relação coletiva de trabalho. Temos como exemplo: as Convenções de n.11 - Direito de sindicalização na agricultura (1921), n.87 Liberdade Sindical e Proteção ao Direito de sindicalização (1948), n. 98 - Direito de Sindicalização e de Negociação Coletiva (1949), n.135 - Proteção de Representantes de Trabalhadores (1971), n.154 - Fomento a Negociação Coletiva (1981), entre outras. (SANTOS, 2019).

Em 1946, ocorreu a vinculação da Organização Internacional do Trabalho (OIT), com a Organização das Nações Unidas (ONU), que havia sido criada em 1945, com o propósito de promover a justiça social no âmbito de questões do trabalho internacional. (SANTOS, 2019). 
Em seguida, com a Declaração Universal dos Direitos Humanos (DUDH), de 1948, realizou-se um importante avanço para a proteção do trabalho e atuação dos sindicatos, estabelecendo o direito à liberdade de reunião e de associação pacífica, além de instituir que o labor deve propiciar ao indivíduo um nível de vida suficiente para lhe assegurar e à sua família a saúde e o bem-estar, principalmente, quanto à alimentação, ao vestuário, ao alojamento, à assistência médica e ainda, quanto aos serviços sociais necessários.

No Brasil, para entender o sindicalismo, é preciso perquirir o momento político e econômico em que o movimento está inserido.

Com chegada dos europeus ao Brasil, foi introduzida a prática do trabalho escravo, um trabalho implantado com base na desumanização do homem negro e indígena, que era visto como inferior, como um animal sem alma e, portanto, sem direitos. Em 1888, houve um importante marco para a história do trabalho no país, com a necessária e tardia abolição da escravatura pela Lei Áurea, que extinguiu a escravidão. (BRITO FILHO, 2019).

Este marco possui grande relevância para a construção da sociedade brasileira, que ainda luta para se desvencilhar do enraizamento de traços racistas e preconceituosos de um período atroz.

Posteriormente, a abolição da escravidão deu espaço ao trabalho assalariado, passando a ser utilizado a mão de obra do imigrante europeu que chega ao Brasil com uma certa experiência de luta de classe, adquirida da Revolução Industrial, que aconteceu nos séculos XVIII e XIX. (FERREIRA, 2008).

Em razão da bagagem de lutas trazida da Europa, lugar onde já havia inicializado o processo de busca por melhores condições de trabalho a partir da manifestação e organização do proletariado, os imigrantes se tornam os principais percussores do movimento sindical no Brasil.

Devido a tal fato foi desencadeada no século XX, a criação de normas que versassem sobre a matéria sindical, com os decretos de números 979, do ano 1903, e 1637, de 1907. (SANTOS, 2019).

O Decreto 979 de 1903, instituía a possibilidade dos profissionais da agricultura e indústrias se organizarem em sindicatos para a defesa de seus interesses, sendo livres de quaisquer restrições, apenas tendo como condição o registro da entidade sindical no cartório do respectivo distrito.

Tais avanços não tiveram continuidade, quando, em 1926, no período do republicanismo oligárquico, Washington Luiz foi eleito presidente pela burguesia rural conservadora que, nessa linha, considerava a questão social um caso de polícia. (SANTOS, 2019).

Essa linha de pensamento discrimina e marginaliza o movimento sindical, fazendo com que os trabalhadores sejam reprimidos e controlados para aceitar quaisquer condições na relação laboral, ainda que desfavoráveis.

A estrutura sindical passa a ser regulamentada em 1930, durante os governos de Getúlio Vargas, com a criação da legislação que trazia como característica predominante, o controle pelo estado nas organizações sindicais em todos os aspectos: financeiros, organizacionais, políticos e ideológicos. (TAPAJOS; ROMERO, 2018). 
Getúlio Vargas implantou no seu governo o modelo corporativista destacado pela manutenção dos grupos de representação próximos ao controle estatal, visando alcançar a paz social, se preocupando em atingir um consenso, inclusive, entre as classes mais desfavorecidas. (MENDES, 2018).

Embora o governo Vargas tenha sido marcado por realizar mudanças expressivas na seara trabalhista, foram mantidos, como diretriz principal, o controle e a repressão dos trabalhadores, que poderiam se organizar somente dentro dos moldes limitantes determinados pelo Estado.

Para tanto, fez-se necessária a criação de uma instituição com a finalidade de fiscalizar as leis existentes, sendo criado por meio do Decreto 19.770, de 1931, o Ministério do Trabalho, Indústria e Comércio, que foi acompanhado de uma forte propaganda, ficando conhecido como o Ministério da Revolução. (NASCIMENTO, 2013).

Em 1934, a Constituição Federal reconheceu os sindicatos no artigo 120 e, no artigo 121, alínea "j", as convenções coletivas de trabalho.

Já em 1937, a Constituição Federal tratou do trabalho como um dever social, conforme artigo 136, e a greve continuou proibida, de acordo com texto do artigo 139, sob a alegação de que a paralisação seria um recurso antissocial, nocivo ao trabalho e incompatível com os interesses do sistema produtivo brasileiro.

Em 1942, o Decreto de número 10.358 declarou estado de guerra e suspendeu os direitos da Constituição Federal de 1937.

Vale ressaltar que o mundo passava por uma onda de governos totalitários, com a Alemanha de Hitler e a Itália de Mussolini, que influenciaram fortemente o governo Vargas no período chamado de Estado Novo. (MENDES, 2018).

No entanto, em 1943, foi criada a Consolidação Das Leis Do Trabalho, pelo Decreto 5.452/1943, denominado assim por consolidar diversas leis esparsas. O modelo sindical brasileiro ficou regulamentado nos Títulos V- Da Organização Sindical e VI- Das convenções Coletivas de Trabalho, no mencionado dispositivo legal.

O modelo corporativista, implantado no Brasil, era marcado pelas características descritas a seguir:

i) necessidade de prévia autorização estatal para aquisição de persona-
lidade sinal; ii) expedição da carta sindical para comprovação dos regis-
tros; iii) convenção coletiva com a natureza de lei delegada; iv) eficácia
erga omnes das cláusulas normativas, conferindo validade do acordo
para todos os trabalhadores; v) poder normativo da justiça do trabalho,
o que possibilita a criação de normas pelo judiciário através das ações
denominas dissídio coletivo. (SANTOS, 2019, p.26-27).

Apesar do significativo progresso que houve com a elaboração da Consolidação da Leis do Trabalho, o modelo corporativista, que em partes ainda se mantém, provoca uma falsa sensação de liberdade sindical.

Dessa forma, a Consolidação Das Leis Do Trabalho (CLT) engessa os sindicatos, que exercem somente uma função assistencialista, passando a ser considera- 
dos um "sindicato de Estado", impedido de exercer com efetividade a representação dos interesses dos trabalhadores. Destaca-se ainda que seu principal meio de reivindicação - se não único - a greve, era terminantemente proibida, deixando o movimento sem voz.

Após avanços e retrocessos, os sindicatos logo sofreram um novo abalo com o golpe militar de 1964. Com os militares assumindo o poder, o Brasil deixava de ser uma democracia e passava a não ter novas eleições. (TAPAJOS, ROMERO, 2018).

Com a ascensão dos militares ao poder, iniciou-se uma época angustiante, em que com a retirada dos direitos a sociedade foi calada, oprimida e feita refém dos mais diversos abusos.

Com o totalitarismo instaurado, quem estava no poder escolhia o que o povo podia ou não fazer, falar, escrever, cantar e até mesmo pensar. Nesse quadro, decidiram que as greves, hoje consideradas um dos principais meios de luta e manifestação de vontade e opinião, fossem determinantemente proibidas. (TAPAJOS, ROMERO, 2018).

Nos governos anteriores, a greve que era vista como um desserviço tornou-se então categoricamente ilícita, e os transgressores estariam fadados a sofrer graves consequências. O que ocorreu, com a prisão, morte e desaparecimento de inúmeros trabalhadores, cidadãos cujo caráter deveras poderia ser considerado de bem, ou ainda que de teor duvidável, não tiveram direito de defesa por meio do devido processo legal, como pode-se ver alguns de seus nomes hoje homenageados no Memorial de Mortos e Desaparecidos da Ditadura. (Memorias da Ditadura, 2020).

Em tal conjuntura, o Brasil passava por uma grave crise econômica e, naquele momento, começou a desenvolver a prática do sindicalismo na porta de fábrica, fazendo com que a categoria operária alcançasse um considerável crescimento, se concentrando na região do ABC. Em 1973 surge a CUT (Central Única dos Trabalhadores), com a finalidade de unificar todos os trabalhadores independentemente de categoria. (TAPAJOS; ROMERO, 2018).

A atividade desenvolvida resultou em uma forte aproximação dos trabalhadores com os representantes de sua categoria, o que foi primordial para a mobilização e notoriedade do movimento sindical.

Ainda na ditadura militar, o plano econômico criado por Delfim Neto fracassou, gerando uma inflação altíssima, o que culminou mais para os movimentos das Diretas Já; e pela primeira vez em duas décadas houve eleições com os civis, Tancredo Neves e Paulo Maluf, este último, como candidato apoiado pelos militares, que disputavam as eleições por meio dos colégios eleitorais. O vencedor foi Tancredo Neves, que faleceu logo em seguida (TAPAJOS; ROMERO, 2018).

Com a crise no modelo econômico implantado no período ditatorial, ocorreu o esgotamento de um sistema que não produziria mais resultados, tornando necessário o surgimento de um novo sistema, que atendesse às necessidades do povo e restabelecesse direitos anteriormente retirados.

Foi elaborado em 1987, o Projeto de Lei n. 164, que discorria sobre uma reforma sindical que colocaria fim ao modelo corporativista, para introduzir a plura- 
lidade sindical e reformular de maneira gradativa a contribuição sindical; porém não foi tratada como prioridade, e o silêncio diante do projeto fez com que esse não fosse levado adiante. (MENDES, 2018).

Na construção da Constituição Federal de 1988, foi votado a favor da preservação da unicidade sindical, com 323 votos a favor, contra 100 votos vencidos, 42 abstenções e 71 ausentes (MENDES, 2018).

A Constituição Cidadã de 1988, foi promulgada com importantes artigos para o direito do trabalho: o artigo $7^{\circ}$ que prevê direitos aos trabalhadores rurais e urbanos, além do reconhecimento dos acordos e convenções coletivas; o artigo $8^{\circ}$ que dispõe sobre o sistema sindical brasileiro; o $9,^{\circ}$ sobre o direito de greve e o $10^{\circ}$ e $11^{\circ}$ sobre a forma de representação dos trabalhadores dentro das empresas, que só veio a ser regulamentada em 2017 com a Lei 13.456, que será abordada adiante.

Com o princípio da liberdade sindical, estabelecido no artigo $8^{\circ}$, ocorreu o esvaziamento de inúmeros artigos da Consolidação Das Leis Do Trabalho (CLT), que tratavam da intervenção estatal quanto àorganização interna dos sindicatos. (SANTOS, 2019).

Os anos 1990 foram marcados pelo desemprego e pela sensação de insegurança, de não haver regras que assegurassem direitos e estabilidade aos trabalhadores. Noperíodo é implantado nas empresas o modelo Toyotista ${ }^{1}$ de produção, que funcionava diferente dos modelos Fordista e Taylorista ${ }^{2}$ - que viam o trabalhador como pessoa xucra e só lhes interessava a força de trabalho que essa despendia, voltados sempre na quantidade de produção. O novo modelo passou a integrar os operários como parte do desenvolvimento do capital, diminuindo o número dos mesmos nas fábricas, e estabeleceu uma comunicação com este trabalhador. (TAPAJOS; ROMERO, 2018).

Com essa medida, o operário passa a desenvolver o sentimento de pertencimento e a enxergar o trabalho de modo individual, o que enfraqueceu o movimento sindical, pelo fato de que se os trabalhadores são vistos como coletivo e sentem-se parte do grupo, logo todos lutam por um objetivo em comum em benefício de todos. Em contrapartida, se o trabalhador é visto como indivíduo e se sente desta forma, busca somente os interesses individuais.

Desta forma, houve uma reestruturação produtiva, incentivando o individualismo e cerceando, em partes, o sentimento coletivo provocado nos trabalhadores. Contudo, não foi nada além do que uma mudança natural trazida pela nova tecnologia e da adequação do modelo de produção à população consumerista.

Quando, em 2002, Luiz Inácio Lula da Silva (que já havia sido derrotado em eleições passadas), foi eleito presidente da República, encontrando o país quebrado economicamente, passou-se então a implementar políticas de estímulo à demanda e incentivo ao consumo. (TAPAJOS; ROMERO, 2018).

1 Toyotismo é o modelo de produção nascido nas fabricas da Toyota. Caracteriza-se pela forma de produção, evitando desperdícios e busca por profissionais qualificados que estejam a par de todo o processo de produção (RIBEIRO, 2015).

2 O modelo fordista-taylorista, utiliza-se do modo de produção em massa e alienado, tendo os seus funcionários a função de produzir somente uma parte do produto, a partir de movimentos repetitivos. (RIBEIRO, 2015). 
Nas novas condições propiciadas pelo governo de esquerda, defendidas pelo Partido dos Trabalhadores (PT), os sindicatos voltaram a crescer e passaram a dialogar com diversas esferas do Poder Executivo, enquanto antes seu contato era somente com o Ministério do Trabalho. Tal fato representou um grande avanço e quebra das limitações historicamente impostas, passando a existir um sindicalismo livre e capaz de representar os interesses dos trabalhadores.

Diante deste novo cenário, as greves, que antes eram feitas com objetivo defensivo para garantir o mínimo conquistado (com pautas como pagamento de salários atrasados e contra demissões), passaram a ter por objetivo novas melhorias nas condições de trabalho, devido o apoio fornecido pelo governo de Lula.

Abriu-se uma nova fase para o sindicalismo e as políticas implantadas impactaram positivamente na economia e melhoraram a vida do trabalhador.

Mesmo assim, o governo falhou na falta de reformas estruturais, rachando o movimento mais uma vez. O Brasil é o país com maior número de sindicatos no mundo, sendo injustificável essa soma. $\mathrm{O}$ crescimento do número de entidades não é proporcional ao aumento de sindicalizados, e nem se leva em consideração que algumas categorias desaparecem com a modernização e o surgimento de novas modalidades de trabalho.

Contudo, observa-se que o sindicalismo surgiu no mundo de uma maneira natural diante das mudanças e evoluções do mercado de trabalho.

\section{A ATUAÇÃO SINDICAL APÓS O ADVENTO DA LEI N. 13.467/2017}

Ao analisar a história, se torna notória a importância de um sistema de relações de trabalho democrático, que vise garantir a igualdade e o direito à participação da criação de normas regulamentadoras das relações de trabalho, tendo em mente que equidade é tratar dignamente os iguais e desigualmente os desiguais, na medida de suas desigualdades, sendo o sindicato detentor da capacidade de igualar funcionário e empregador, fazer com que sua voz seja ouvida e seu direito, respeitado, por meio da força do coletivo.

No direito, existe a premissa de que os ordenamentos jurídicos devem se voltar para a proteção da parte considerada hipossuficiente, com a finalidade de criar entre as partes uma posição de paridade, para que os meios de obter justiça sejam viáveis para todos, de acordo com as suas diferenças e desproporcionalidades.

Ao examinar o artigo $1^{\circ}$, inciso III da Constituição Federal de 1988, nota-se que se trata de um tema ético e moral, no qual se fundamentam todas as demais normas presentes na carta magna.

De acordo com o parecer proferido pela comissão especial destinada a pronunciar entendimento ao projeto de Lei $\mathrm{N}^{\mathrm{o}} 6.787$, de2016, a justificativa do governo para aprovação da reforma trabalhista veio da necessidade de modernizar a Lei n. ${ }^{\circ}$ 6.019, de 1974, que trata do trabalho temporário, de regulamentar o artigo 11 da Constituição Federal que dispõe sobre a constituição de representantes dos trabalhadores dentro da empresa e de aprimorar as relações do trabalho no Brasil, por meio da valorização da negociação coletiva entre trabalhadores e empregadores junto de outros pontos alterados. 
Foi instituída uma comissão especial destinada à análise da proposta, com o proferido parecer no dia 10 de abril de 2017, cujo relator concluiu em seu voto:

\begin{abstract}
Novas profissões surgiram e outras desapareceram, e as leis trabalhistas permanecem as mesmas. Inspirada no fascismo de Mussolini, as regras da Consolidação Das Leis Do Trabalho (CLT) foram pensadas para um Estado hipertrofiado, intromissivo, que tinha como diretriz a tutela exacerbada das pessoas e a invasão dos seus íntimos. O respeito às escolhas individuais, aos desejos e anseios particulares é garantido pela nossa Lei Maior. Não podemos mais negar liberdade às pessoas, não podemos mais insistir nas teses de que o Estado deve dizer o que é melhor para os brasileiros negando-os o seu direito de escolher. Precisamos de um Brasil com mais liberdade. (BRASIL, Comissão Especial Destinada A Proferir Parecer Ao Projeto De Lei Nº 6787, de 2016. Relator: (MARINHO, 2017, p.17).
\end{abstract}

Demonstra-se o interesse em reduzir a proteção institucional aos trabalhadores, por parte do Estado e do sindicato e aumentar as garantias, a autonomia e a flexibilidade para as empresas nas relações de trabalho, uma maneira de, ao mesmo tempo, reduzir a proteção institucional e expandir a liberdade do capital.

Entretanto, o termo "tutela exacerbada" deve ser esquadrinhado com cautela, por se tratar de um tema importante e delicado. É preciso examinar até onde a tutoria do Estado deve alcançar a vida do indivíduo, quando o coletivo não deve sobrepor à liberdade de escolha sem que o interesse geral seja prejudicado e observar os limites estabelecidos pela Constituição Federal de 1988, levando em consideração que a discussão temática gira em torno de uma reforma que trata de direitos trabalhistas, dos quais discerne sobre uma relação de emprego em que uma das partes é considerada hipossuficiente diante do sujeito detentor do poder econômico.

Vale ressaltar que a mudança legislativa ocorreu em um período de instabilidade política e econômica, após o impeachment da até então presidente Dilma Rousseff, sobrevindo à transformação da Consolidação Das Leis Do Trabalho, em curto período para a apreciação e análise adequada.

A reforma foi colocada como o meio necessário para o Brasil retomar o crescimento; no entanto, mesmo após aprovada, o cenário continua o de um mercado enfraquecido, com recente número de desempregados, visto que as razões de ordem política estão diretamente vinculadas à recuperação da economia, pois o encaminhamento destas questões são de competência do Poder Executivo, cujo governo ainda tenta encontrar estabilidade.

A Lei de $n^{\circ} 13.467$ entrou em vigor em 11 de novembro de 2017, sendo, até o momento, editadas duas Medidas Provisórias: a de $n^{\circ} 808$ e 873, tornando a reforma trabalhista um tema recente que ainda produz inúmeros debates, visto que questões continuam em aberto no tocante à aplicação de alguns dispositivos legais, previstos na Consolidação das Leis Trabalhistas.

Todavia, vale lembrar que é princípio basilar do direito do trabalho a imperatividade das normas trabalhistas, que consagra a ideia de que são de ordem 
pública e de caráter cogente, não podendo ser afastadas pela vontade das partes (MENDES, 2018, p 102).

Essa característica traz à tona um dos princípios núcleos de toda a estrutura do direito trabalhista, tanto individual como coletivo, que é o protecionismo da parte vulnerável na relação de emprego.

Com a crise provocada pela pandemia do Covid-19, a situação do trabalhador se tornou ainda mais temerária, com medidas que não priorizam de fato a manutenção do emprego e da renda, mas sim, a estabilidade financeira das empresas.

Para melhor compreender as alterações e os seus impactos, é necessário identificar as diferentes formas de atuação inerentes às entidades sindicais, e o desenvolvimento de suas atividades.

\section{FUNÇÕES SINDICAIS}

No mesmo grau de importância, que é o estudo da história e evolução do sindicalismo, também é fundamental identificar as diferentes formas de atuação inerentes às entidades sindicais e o desenvolvimento de suas atividades.

Como argumenta Nascimento (2013), os sindicatos são a base do direito coletivo, funcionando como entidades associativas permanentes que representam os trabalhadores, visando a defesa de interesses coletivos.

O artigo $8^{\circ}$, inciso III da Constituição Federal de 1988, dispõe que ao sindicato cabe a defesa dos direitos e interesses coletivos ou individuais da categoria, inclusive em questões judiciais ou administrativas, tendo sido ratificado na Consolidação Das Leis Do Trabalho em seu artigo 513.

Brito Filho (2019) explica que existe uma certa uniformidade na doutrina, na maneira de dividir o tema, sendo que dois grandes doutrinadores, Amauri Mascavo Nascimento e Octavio Bueno Magano, dividem a atuação sindical nas funções: negocial, assistencial, política, econômica e representação processual.

Esses encargos devem ser executados com o único objetivo de cumprir a finalidade da existência dos sindicatos, que é representar os interesses da categoria.

A função econômica está relacionada com a receita do sindicato e as formas de arrecadação para desenvolver suas atividades e pode ser interpretada em duas vertentes: a primeira seria em sentido amplo, que trata das formas de arrecadação admitidas em lei; já a segunda seria em sentido estrito, que se daria pelo desenvolvimento dos sindicatos nos setores industrial, comercial e de serviços. (BRITO FILHO, 2019).

As fontes de receita das entidades sindicais são divididas em quatro: 1) contribuição social; 2) contribuição sindical; 3) contribuição confederativa e 4) contribuição assistencial.

A contribuição social, também denominada de mensalidade sindical, está prevista no supramencionado artigo 548, b, da Consolidação Das Leis Do Trabalho (CLT), estando ligada diretamente ao direito de associação. Esta deveria ser a principal fonte de arrecadação dos sindicatos, porém como antes da reforma trabalhista era possível aumentar a renda sem a conquista de novos associados, era preferível por alguns dividir o custeio com os não associados (BRITO FILHO, 2019).

A contribuição sindical era cobrada anualmente de maneira compulsória de 
trabalhadores e empregadores, equivalendo ao valor de um dia de trabalho, geralmente cobrado no mês de março.

Entretanto, a Lei 13.467/2017 mudou a forma de cobrar a contribuição sindical obrigatória, que estava regulamentada há mais de sete décadas pela Consolidação Das Leis Do Trabalho (CLT), sem que fosse estabelecido um período de transição para que houvesse uma adaptação por parte das entidades sindicais.

Agora, por força do artigo 579 da Consolidação Das Leis Do Trabalho (CLT), com redação dada pela reforma trabalhista, a sua cobrança depende de autorização prévia e expressa dos que participarem de uma determinada classe econômica ou profissional, ou de uma profissão liberal, em favor do sindicato representativo da mesma categoria.

Para Brito Filho (2019), esta, que durante décadas, fora a principal fonte de renda dos sindicatos, agora, dificilmente, será arrecadada em larga escala como outrora. Entendia-se que a obrigatoriedade feria a liberdade sindical individual dos não associados, que eram forçados a pagar.

Essas alterações aconteceram em um cenário com aproximadamente 16,5 mil sindicatos no Brasil, em 2017, sendo que desse número, 11,2 mil são sindicatos profissionais. (IPEA, 2017).

Nos primeiros anos após o fim da contribuição sindical obrigatória, os sindicatos tiveram seus recursos reduzidos em $90 \%$, passando de uma arrecadação de R \$ 2,24 bilhões, para R \$207,6 milhões. (SANTOS, 2019).

Brito Filho (2009) comenta que a terceira contribuição é a confederativa, que possui a finalidade de custear o sistema confederativo, existindo por liberalidade dos sindicatos e por força da constituição, como forma de unificar a luta das categorias na esfera nacional, sendo devida apenas pelos associados.

Por último, e não menos importante, a contribuição assistencial leva como essência a solidariedade com os trabalhadores da causa, como forma de fortalecer as entidades sindicais, sendo utilizada para promover campanhas para o estabelecimento de convenções coletivas. (BRITO FILHO, 2019).

Apesar da existência das demais contribuições, ocorreu uma grande e impactante mudança com o fim da obrigatoriedade da contribuição sindical -é incontestável o enfraquecimento de seu poder econômico.

Já a função negocial, ou também conhecida como regulamentar, preconiza umas das principais atividades exercidas pelos sindicatos. Esta se concretiza na celebração de acordos e convenções coletivas.

Tal atribuição conferida aos sindicatos, está prevista nos artigos 513, b, 611 a 625 da Consolidação Das Leis Do Trabalho (CLT). Sendo assim:

[...]o campo das negociações coletivas talvez seja o único caminho seguro a ser percorrido para o aprimoramento das combalidas relações de trabalho brasileiras. Os avanços pela via legislativa estão esgotados e quanto mais proliferam as leis e decretos - normas heterônomas - tanto mais descontrole surge na interpretação e tanto mais súmulas e orientações têm de ser providenciadas pelos tribunais trabalhistas. Os instru- 
mentos normativos - normas autônomas - ostentam a virtude indiscutível da imediatidade, bem assim a especificidade para o atendimento das demandas e a solução harmônica dos conflitos. Fora isso, uma vez firmados, os instrumentos carregam subjacentes a eles uma espécie de cláusula de pacificação social, pois não se pode ficar rediscutindo as cláusulas indefinidamente. Contanto que elas sejam cumpridas, duram o prazo de vigência ajustado entre as partes - normalmente, um ano - e evitam o desassossego no período (SILVA, 2019, p.266 -267).

Seria este um método autocompositivo para encontrar um consenso para os conflitos coletivos, que se desdobram na função obrigacional de criar direitos e obrigações entre as partes, política e de fomentar o diálogo e aproximação entre as classes.

Para que a negociação seja eficiente, deverá observar o cenário econômico e social, contando com a participação dos trabalhadores nas tomadas de decisões pertinentes ao interesse coletivo. (SANTOS, 2019).

Para proveito da negociação coletiva é necessário que princípios sejam observados, utilizando como núcleo base a dignidade da pessoa humana (artigo $1^{\circ}$, III, $\mathrm{CF}$ ), a cidadania e os valores sociais do trabalho (artigo $1^{\circ}$, II e IV, CF), com objetivos que visem a construção de uma sociedade justa e solidária, para a garantia do desenvolvimento nacional, a erradicação da pobreza, a promoção da ordem econômica e viabilização do bem de todos. (SANTOS, 2019).

A mudança, trazida pelo novo artigo 611-A, permite que o sindicato possa se tornar adversário dos trabalhadores, podendo ser negociado de forma que suprima diversos direitos fixados na ordem jurídica, por exemplo: banco de horas anual, teletrabalho, trabalho intermitente, participação de lucros e resultados da empresa, entre outros.

A reforma trabalhista trouxe a possibilidade de que o negociado prevaleça sobre o legislado, porém essa tese não deve ser considerada absoluta e precisa ser interpretada a partir da análise dos princípios, que possuem força normativa. Desta forma, nenhum pacto coletivo poderá violar direitos fundamentais. Devem ser observados os direitos à previdência, saúde, educação, entre outros. Não pode contrariar os direitos mínimos previstos nos artigos $7^{\circ}$ a 11 da CF/1988. (SANTOS, 2019).

Outra relevante alteração foi no tocante à ultratividade, que significa a aplicação de uma norma após o prazo de sua vigência -vedada conforme artigo 614 §3 da Consolidação Das Leis Do Trabalho (CLT).

A função assistencial é um importante meio de atuação com viés social, para auxílio de seus representados na busca por melhores condições de vida.

Esta função é atribuída aos sindicatos pela lei ou pelos estatutos, para prestar serviços aos seus representados e contribuir para o desenvolvimento integral do ser humano. (SANTOS, 2019).

Dentro dessa função consiste a atividade de fiscalizar, conforme aponta Santos (2019), dentro do exercício da fiscalização estava a homologação das rescisões contratuais dos empregados com mais de um ano na mesma empresa, sendo revogados do artigo $477 \S \S 1^{\circ}$ e $3^{\circ}$ e $7^{\circ}$ da Consolidação Das Leis Do Trabalho (CLT), passando a ser facultativa ou prevista em acordos coletivos. 
Os sindicatos desempenhavam um papel de extrema importância no procedimento de homologação, pois eram investidos de poder que se equipara ao do empregador para pleitear que os direitos devidos fossem efetivamente pagos.

Pode-se definir o objetivo da homologação como buscar a justiça e a equidade entre empregados e empregadores. Como é de conhecimento, justiça é dar a cada um o que lhe é devido, sendo, no procedimento de homologação, assegurar que o trabalhador receba todos os valores pelos quais tem direito, sem a necessidade de ingressar com processo judicial.

Essa alteração chegou em conjunto a uma novidade questionável, o estabelecimento de "termo de quitação anual de obrigações trabalhistas", que pode ser celebrado, periodicamente, durante a vigência do contrato de trabalho perante o sindicato, sendo que este poderá se opor. (novo artigo 507-B da Consolidação Das Leis Do Trabalho (CLT).

$\mathrm{O}$ artigo $8^{\circ}$, inciso III, preleciona que ao sindicato cabe a defesa dos direitos e interesses coletivos e individuais da categoria; logo, subtende-se que esses estão investidos da competência necessária para representar os seus trabalhadores.

A representação pode ser dividida quanto à área de atuação em judicial e extrajudicial. Judicialmente a representação pode ser tanto em favor de toda categoria, e em outras somente dos associados. (BRITO FILHO, 2019).

Para Santos (2019, p), a Lei n. 13.467/2017 nada mudou em relação à postulação judicial do sindicato em prol dos interesses individuais ou coletivos da categoria.

No entanto, a lei citada compartilhou a função de representação com outros representantes não sindicais, como as comissões de empresa, através da inserção dos artigos 510-A a 510-D, na Consolidação das Leis de Trabalho (CLT).

O artigo 11 da Constituição Federal de 1988 já falava a respeito da representação dentro das empresas ao dispor que nas empresas de mais de duzentos empregados, é assegurada a eleição de um representante dos trabalhadores com a finalidade exclusiva de promover-lhes o entendimento direto com os empregadores. Porém, essa temática não foi regulamentada por legislação infraconstitucional até o ano de 2017.

A representação dos trabalhadores na empresa também está definida no artigo $3^{\circ}$ da convenção $n^{\circ} .135$ da Organização Internacional Do Trabalho, ratificada pelo Brasil em 1991. (SANTOS, 2019).

Contudo, é relevante mencionar que o atual modelo sindical atravessa um momento de crise de representatividade, que se dá pelo fato de os dirigentes não implantarem o desejo da maioria de seus representados.

Para Mendes (2018), a solução para essa crise seria a aproximação dos sindicatos em um modelo democrático ampliado, resgatando assim a sua força reivindicatória para conceder voz ao maior número de atores sociais.

Os trabalhadores não se identificam com os sindicatos das suas categorias, pois consideram que alguns líderes sindicais desenvolvem suas funções com o interesse pessoal de se perpetuarem no poder. (MENDES, 2018). 
Bobbio (1986 apud MENDES, 2018) ensina que os grupos, e não os indivíduos, são os protagonistas da vida política de uma sociedade democrática, que a capacidade reivindicativa da coletividade depende do engajamento dos indivíduos que a compõe. Os estudiosos entendem que a representação só será efetiva se satisfizer os interesses dos diversos atores, o que reforça a imprescindibilidade das entidades sindicais que, atualmente, precisam se engajar para que seus representados se identifiquem com os interesses por elas buscados.

Visto as principais funções e suas respectivas alterações advindas com a Lei 13.467/2017, cabe dizer que as mudanças no cenário sindical não cessaram com a reforma trabalhista, e outras possíveis alterações ainda estão em debate. A prova disso é a Portaria $N^{\circ} 1.001$, de 4 de setembro de 2019, instituída pelo governo federal para estudar as relações trabalhistas e o seu futuro com o objetivo de modernizá-las.

Para Alberto Emiliano de Oliveira Neto (2019), é possível antever que uma reforma sindical, implantada pelos políticos atuais, contará com a prevalência da pluralidade de associações sindicais, consagrando o previsto pela Convenção de n.87 da Organização Internacional Do Trabalho. A arrecadação financeira somente a partir da contribuição associativa; o viés assistencialista será prejudicado pela redução extrema da receita; convenção coletiva com maior flexibilização de direitos; dificuldade de implantar a greve, que poderá ser inviabilizada pela ação judicial por meio do interdito proibitório, são as principais questões a serem remodeladas.

$\mathrm{O}$ sindicalismo se encontra em crise, dentro de um contexto de crescente individualização, desregulamentação e flexibilização das relações de trabalho, o que atinge as conquistas históricas do movimento sindical, resulta no esgotamento dos modelos sindicais; na institucionalização que afasta o sindicalismo da radicalidade social e a exaltação do individualismo exacerbado. (NETO,2019).

Para Neto (2019), o que também enfraquece os sindicatos e aumenta a crise é a burocratização, que faz crescer um sindicalismo assistencial, distante dos locais de trabalho. Como resultado, a categoria se sente distante dos seus representantes, sem saber o que de fato eles fazem no dia a dia para atender a finalidade para a qual foram destinados.

Neto (2019) ainda argumenta que não se pode negar que a polarização partidária e o engajamento extremo de seus militantes reduzem o núcleo associativo, pois os sindicatos ficam vinculados aos ideais políticos de uma determinada corrente, fazendo com que os trabalhadores que não se identificam e levantam a bandeira de um partido contrário, abominem as entidades sindicais.

Colocando de maneira mais clara, a forte corrente "antipetista" aumenta a crise de representatividade dos sindicatos entre os trabalhadores oposicionistas politicamente, por entender que o sindicato é uma extensão daquele partido.

Para poder vislumbrar um futuro para os sindicatos, é preciso que esses se desprendam de uma atuação que agrada somente à classe dominante, que é a de um sindicato meramente assistencialista e burocrata. Para que os sindicatos possam se reerguer de forma mais ativa, é indispensável a união dos trabalhadores 
para o enfrentamento dos detentores do capital e a retomada da luta para a ascensão social. (NETO, 2019).

Ao sindicato cabe a defesa dos interesses da classe trabalhadora e esta competência não pode ser dele afastada. (NETO, 2019).

Para que a defesa ocorra de forma eficaz, o sindicato deve traçar estratégias de resistência perante ataques eminentes.

\section{COVID-19 - REPERCUSSÕES DAS MEDIDAS EMERGENCIAIS NO DIREITO SINDICAL}

A sociedade vive um momento ímpar na história, em razão da pandemia Covid-19, ocasionada pelo novo Coronavírus, que impactou o mundo nas mais diversas áreas: sanitária, social, cultural, econômica, humanitária e, consequentemente, o direito, por ser um evento imprevisível, que produz inúmeros efeitos jurídicos.

Trata-se de um momento de exceção, que só pode ser enfrentado com medidas não tradicionais, por meio de ferramentas legais que devem ter por objetivo impedir o avanço da pandemia e regularizar as mais diversas relações, mantendo a ordem na sociedade e as condições mínimas de dignidade inerentes à pessoa humana.

Diante dessa situação e das medidas de contenção do avanço do vírus, surgem novas demandas a serem solucionadas pelo direito do trabalho. A pandemia ocasionou grave crise econômica, gerando no trabalhador forte abalo financeiro e emocional, uma vez que este fica submetido a uma situação de angústia e temor em razão da incerteza do futuro, visto que dois grandes e importantes fatores da vida encontram-se em perigo eminente: a saúde e o trabalho.

Dentro desse ambiente hostil para o empregado, veio a lume a Medida Provisória $\mathrm{n}^{\circ} 927$, de 22 de março de 2020, em seguida, alterada pela revogação de um de seus dispositivos, por meio da Medida Provisória de número 928, de 23 de março de 2020.

A mencionada Medida Provisória surge com o objetivo de agilizar a adoção de mecanismos que deem ao empregador alternativas de modo a diminuir o inevitável abalo financeiro provocado pela crise, trazendo como possíveis soluções a implementação do teletrabalho; a antecipação de férias individuais e feriados; a concessão de férias coletivas. Além dessas, destacam-se também: o banco de horas, a suspensão de exigências administrativas em segurança e saúde do trabalho; o direcionamento do trabalhador para qualificação e o diferimento do recolhimento do Fundo de Garantia do Tempo de Serviço - FGTS.

$\mathrm{O}$ artigo $2^{\circ}$ da MP 927 dispõe que os acordos serão feitos mediante acordo individual, afastando a participação do sindicato profissional, impedindo o trabalhador de estar sob a proteção de um ente investido de poder equiparado ao do empregador.

Em seguida, no dia $1^{\circ}$ de abril de 2020, o presidente da República, Jair Messias Bolsonaro, publicou a Medida Provisória 936, mantendo o princípio de flexibilização ${ }^{3}$ das negociações entre empregadores e funcionários.

3 De acordo com o entendimento doutrinário, a flexibilização é o movimento que visa garantir maior autonomia para adaptação dos empregadores, mantendo somente os direitos mínimos para os empregados.(DELGADO, 2017). 
A referida medida provisória instituí o programa emergencial de manutenção de renda, estabelecendo a possibilidade de o empregador reduzir salários e jornadas em $25 \%, 50 \%$ e $70 \%$, além de autorizar a suspensão dos contratos de trabalho, com complemento do seguro-desemprego e garantia de estabilidade. Assim como a Medida Provisória 927/2020, essas alterações contratuais ocorrem por meio de acordo individual.

Os artigos 611-A e 611-B da CLT - introduzidos pela reforma trabalhista para permitir a possibilidade de a norma coletiva estabelecer uma proteção inferior ao mínimo assegurado em lei - foram aprofundados pela supramencionada Medida Provisória ao buscar o afastamento da atuação sindical para a redução do salário do empregado. (PORTO, 2020).

A Constituição Federal estabelece o princípio da irredutibilidade salarial em razão de seu caráter alimentar, autorizando sua flexibilização unicamente mediante negociação coletiva - artigo $7^{\circ}$, VI e XIII, da CF/ 88 -, enquanto a Consolidação Das Leis Do Trabalho (CLT), em relação a suspensão do contrato de trabalho, enfatiza em seu artigo 476-A que a suspensão do contrato de trabalho também deve ocorrer por meio de negociação coletiva.

Na ADI (Ação Direta de Inconstitucionalidade) de No 6363 (BRASIL, 2020), o ministro Lewandowski, do STF (Supremo Tribunal Federal),em decisão monocrática, proferida em 06 de abril 2020, deferiu parcialmente a cautelar requerida, determinando liminarmente que os acordos individuais previstos na Medida Provisória 936/2020, dependeriam da manifestação dos sindicatos para serem validados.

Entretanto, o plenário do STF (Supremo Tribunal Federal) decidiu em 17 de abril de 2020, pela autorização da redução salarial e suspensão contratual por meio de acordo individual, independentemente da anuência do sindicato da categoria.

Embora o entendimento do Supremo Tribunal Federal tenha se baseado na necessidade de celeridade na resolução dos problemas advindos com a pandemia, o distanciamento dos sindicatos, em um momento de extrema importância e vulnerabilidade, viola expressamente os dispositivos constitucionais mencionados, seguindo a tendência já trazida pela Reforma Trabalhista de desregulamentação ${ }^{4}$ e flexibilização das normas, afastando o empregado da tutela protecionista que é a característica fundadora e norteadora de todo o direito trabalhista.

Contudo, poderia ter sido mais eficaz se a Medida Provisória flexibilizasse os prazos e requisitos previstos no artigo 617 da CLT, o que nas palavras de Cassar (2020) seria autorizar o "acordo coletivo express". Isso facilitaria a negociação das partes em um momento de grande risco de extinção das empresas e empregos, mantendo a representatividade sindical na vida do trabalhador.

Para Joselita Nepomuceno Borba (2020), o afastamento do sindicato ocorreu devido à debilidade que o atinge, ao ponto de o próprio poder público duvidar da sua capacidade representativa.

4 A desregulamentação consiste na retirada, por lei, do manto trabalhista clássico sobre as relações de trabalho, de modo a permitir o império de outro tipo de regência normativa.(DELGADO, 2017). 
Posteriormente, a Medida Provisória 936/2020 foi convertida na Lei de $\mathrm{n}^{\circ}$ 14.020, publicada em 07 de junho de 2020, tendo em seguida a publicação do Decreto 10.422, de 14 de julho de 2020, que permite a prorrogação dos acordos de redução proporcional do salário e da jornada, bem como a suspensão do contrato de trabalho por até 120 dias. Já a Medida Provisória 927/2020 não foi apreciada pelo Congresso, perdendo a sua validade em 20 de julho de 2020.

A problematização está no fato de que o artigo 468 da Consolidação Das Leis Do Trabalho, ratifica que, nos contratos individuais de trabalho, apenas é lícita a alteração das respectivas condições por mútuo consentimento e desde que não resultem, direta ou indiretamente, em prejuízos ao empregado.

Mas isso não condiz com a realidade, visto que as alterações acontecem de forma unilateral, visando priorizar os interesses do empregador que impõe a sua vontade ao empregado, que se vê desamparado sem a proteção do ente coletivo responsável por representar e defender os seus direitos.

O procedimento adotado para deliberar alterações contratuais, em um cenário de pandemia e fragilidade social, fomenta ainda mais o desequilíbrio nas relações de emprego.

Cassar (2020) aponta que o principal bem jurídico que se pretende proteger é a vida, uma vez que o sistema público não poderia amparar a todos os enfermos, mas que também há muito tempo existe uma forte preocupação em preservar a saúde da empresa para possibilitar a manutenção do emprego.

Nesse sentido, entende-se que a MP 936/2020, que teria como principal objetivo socorrer as empresas, os empregados e a economia, não cumpriu de maneira efetiva a sua finalidade em relação aos trabalhadores que estão a mercê das decisões das empresas que buscam, acima da manutenção do emprego, a sua preservação.

Os números indicados pela Fundação Getúlio Vargas (FGV) demonstram que o número de desempregados no país passou de 12 milhões para cerca de $17 \mathrm{mi}$ lhões, evidenciando a delicada situação de inúmeras famílias que se encontram sem renda (MENDES, 2020).

Nunca antes se fez tão adequada a análise do ilustre professor Brito Filho (2019), segundo o qual a luta dos trabalhadores se reduziu a preservar o mínimo do que foi conquistado ao longo dos anos, sendo o cenário atual marcado pelo desemprego e pela precarização do trabalho.

No entanto, cabe ressaltar que a atuação sindical já está respaldada na Constituição Federal e independe de autorização legal por meio de Medida Provisória para que o sindicato exerça o seu papel. (BELMONTE; MARTINEZ; MARANHÃO, 2020).

Apesar da legitimidade concedida por meio das medidas provisórias aos acordos individuais, estes não prevaleceriam caso houvesse norma coletiva pactuada estabelecendo condições mais benéficas. (BORBA, 2020).

A negociação coletiva continua sendo um instrumento importante. Os trabalhadores assalariados deveriam poder contar com sua maior fonte de força, a união, que se revelou ao longo de toda história ser o único meio eficaz do trabalhador se igualar ao detentor do capital. 
Na atual conjuntura, torna-se urgente e imprescindível a mobilização e o ressurgimento de um sindicalismo forte e combatível.

\section{CONSIDERAÇÕES FINAIS}

O trabalho é imprescindível para o desenvolvimento humano, sendo parte essencial para a construção da vida em sociedade. Relacionadas ao labor estão a honra, a felicidade, a saúde, a busca por sonhos e ideais, sendo que por esse meio as pessoas se realizam como ser humano, conquistam status, qualidade de vida, adquirem condições para constituir família e obtêm propriedades.

Por esse motivo, é fundamental que seja garantido um ambiente saudável e humano que proporcione ferramentas para a evolução e bem-estar do indivíduo.

Diante o exposto, fica demonstrado, conforme análise histórica, que o trabalhador merece guarida pela desigualdade econômica existente entre capital e trabalho, pois enquanto o último busca melhores condições de vida, o empregador segue no objetivo de obter o maior lucro possível.

Portanto, é preciso que exista a figura de uma entidade investida de poder equiparado ao do empregador, que seja responsável por intervir na relação para que a busca pelo lucro aconteça sem a exploração do proletariado. A personalidade sindical é extremamente necessária no mundo capitalista.

Os sindicatos são indispensáveis para o alcance do equilíbrio nas relações de trabalho, para a proteção e defesa do trabalhador.

Entretanto, é incontestável que de fato ocorreu o enfraquecimento dessas entidades. O principal motivo se deu pelo fato de que as alterações não aconteceram de forma gradual, a fim de permitir que os sindicatos se reorganizassem estruturalmente.

A estrutura sindical, que até então se conhece, é arcaica, herdade de um regime totalitário, inspirado na Carta Del Lavoro de Mussolini, o que não se enquadra no Estado democrático de direito, na qual o Brasil está constituído.

A origem corporativista fez com que muitos sindicatos se acomodassem, pois, com a contribuição sindical obrigatória, sua subsistência não carecia de resultar do trabalho desenvolvido e do esforço desprendido na luta pelos interesses da respectiva categoria.

Como consequência, nota-se uma estagnação dessa entidade que não buscou cativar os seus representados, de forma que esses, hoje, não se identificam com os líderes sindicais.

Com o incentivo à busca pelos anseios individuais e o distanciamento dos trabalhadores de seus sindicatos, vive-se uma crise de representatividade. A consciência de classe foi abalada, sendo necessário que as entidades sindicais mudem a sua imagem e se aproximem novamente do trabalhador.

As alterações advindas da Lei 13.467/2017 trouxeram mudanças na forma do sindicato desenvolver suas atividades, porém é de se esperar que, dentro do atual cenário pandêmico, essa associação que teve sua participação reduzida e posteriormente descartada venha a se rearticular para buscar novos meios para, assim, não desguardar o trabalhador. 
A infelicidade da reforma, em relação aos sindicatos, foi no tocante à celeridade que as medidas foram aplicadas, o que inevitavelmente prejudicou as entidades sindicais, uma vez que as discussões sobre a necessidade das alterações vinham sendo fomentadas há décadas, nunca sendo levadas adiante.

A Lei 13.467/2017 e as medidas emergenciais adotadas em razão da pandemia não oferecem as ferramentas necessárias para que os sindicatos permaneçam presentes da vida dos trabalhadores.

A legislação, que flexibiliza direitos e mitiga a atuação sindical, deve tão logo ser refutada. Há uma importância ímpar na atuação sindical. Todavia, a descredibilização que sofre o sindicato, pelos próprios trabalhadores, dificulta a defesa e a luta pela garantia dos direitos. O que deve ser feito é o debate sério e competente, para que o sindicato assuma o protagonismo novamente e, entre erros e acertos, esteja presente para que seja combatente quando o assunto for a proteção de direitos, principalmente nesse momento de crise.

\section{REFERENNCIAS}

AROUCA, José Carlos. Organização Sindical no Brasil: Passado, Presente - Futuro (?). São Paulo: $2^{\mathrm{a}}$. ed. LTr, 2019.

BELMONTE, Alexandre Agra; MARTINEZ, Luciano; MARANHÃO, Ney. O Direito do Trabalho na crise da COVID-19. Salvador: Editora JusPodivm, 2020. Disponível em: http://www.abmtrab.com.br/_arquivos/Direito_do_Trabalho_na_Crise_da_Covid19. pdf/ Acesso em 17. Ago. 2020.

BORBA, Joselita Nepomuceno. Covid-19 e fragilidade do sindicato. É possível o poder público ingerir na atuação sindical para, em meio à força maior qualificada, anular aditivo a convenção coletiva de trabalho? São Paulo: Academia Brasileira de Direito do Trabalho. Disponível em: http:/ / www.andt.org.br/f/COVID-19\%20e\%20fragilidade\%20do\%20sindicato-Lita.pdf. Acesso em 20 de ago. 2020.

BRASIL, Comissão Especial Destinada A Proferir Parecer Ao Projeto De Lei No 6787, De 2016.Voto do Relator: MARINHO,2017. Disponível em:. https:/ / www.camara.leg.br/proposicoesWeb/prop_mostrarintegra?codteor=1544961 Acesso em 09 de nov de 2020.

BRASIL, Consolidação Das Leis Do Trabalho 1943. Disponível em: http:/ / www.planalto. gov.br/ccivil_03/Decreto-Lei/Del5452.htm. Acesso em 30 de ago. de 2019

BRASIL, Constituição do Império de 1824. Disponível em: http:/ / www.planalto.gov.br/ ccivil_03/Constituicao/Constituicao24.htm. Acesso em 10 de nov. de 2019.

BRASIL, Constituição Federal de 1934. Disponível em: http:/ /www.planalto.gov.br/ccivil_03/constituicao/Constituicao34.htm. Acesso em 10 de nov. de 2019.

BRASIL, Constituição Federal de 1937. Disponível em: http://www.planalto.gov.br/ccivil_03/Constituicao/Constituicao37.htm. Acesso em 10 de nov. de 2019.

BRASIL. Constituição de 1988. Disponível em: http://www.planalto.gov.br/ccivil_03/ Constituicao/Constituicao.htm. Acesso em 05 de ago. de 2019. 
BRASIL. Decreto 979 de 1903. Disponível em: http:/ / www.planalto.gov.br/CCIVIL_03/ Decreto/Antigos/D0979.html. Acesso em 02 de set. de 2019.

BRASIL. Decreto 1637 de 1907. Disponível em:https:/ / www2.camara.leg.br/legin/fed/ decret/1900-1909/ decreto-1637-5-janeiro-1907-582195-publicacaooriginal-104950-pl.html. Acesso em 2 de set. de 2019

BRASIL. Decreto 10.422 de 2020. Disponível em: http:/ / www.planalto.gov.br/ccivil_03/_ Ato2019-2022/2020/Decreto/D10422.htm\#: :text=DECRETO\% 20N\% C2\% BA \% 20 $10.422 \% 2 \mathrm{C} \% 20 \mathrm{DE} \% 2013,6 \% 20 \mathrm{de} \% 20 \mathrm{julho} \% 20 \mathrm{de} \% 202020$. Acesso em 25 de jul. de 2020

BRASIL. Lei 14.020 de 2020. Disponível em: http://www.planalto.gov.br/ccivil_03/_ ato2019-2022/2020/Lei/L14020.htm\#: :text=Art. \% 201\%C2\%BA\%20Esta \% 20Lei,de\% 20 import\%C3\%A2ncia\%20internacional\%20decorrente\%20do. Acesso em 25 de jul. de 2020 BRASIL. Medida Provisória 927 de 2020. Disponível em: http:/ /www.planalto.gov.br/ ccivil_03/_ato2019-2022/2020/Mpv/mpv927.htm. Acesso em 25 de jul. de 2020

BRASIL. Medida Provisória 928 de 2020. Disponível em:http:/ / www.planalto.gov.br/ccivil_03/_ato2019-2022/2020/Mpv/mpv928.htm. Acesso em 25 de jul. de 2020

BRASIL. Medida Provisória 936 de 2020. Disponível em: http:/ /www.planalto.gov.br/ ccivil_03/_ato2019-2022/2020/Mpv/mpv928.htm. Acesso em 25 de jul. de 2020

BRASIL. Portaria 1.001 de 04 de setembro de 2019. Disponível em: http:/ /www.in.gov. br/web/dou/-/portaria-n-1.001-de-4-de-setembro-de-2019-214576646. Acesso em 02 de nov. de 2019.

BRITO FILHO, José Cláudio Monteiro de. Direito sindical: análise do modelo brasileiro de relações coletivas de trabalho à luz do direito estrangeiro comparado e da doutrina da ORGANIZAÇÃO INTERNACIONAL DO TRABALHO: proposta de inserção da comissão de empresa. 8.ed. São Paulo: LTr, 2019.

CARVALHO, Paulo de Barros: Princípios e sobreprincípios da interpretação do direito. Revista da FESDT, n7.2011 Disponível em: https://www.fesdt.org.br/web2012/revistas/7/7.pdf / Acesso em: 12 de jul. 2019

CASSAR, Vólia Bomfim. Resumo de direito do trabalho. 6. ed., rev., atual. eampl. Rio de Janeiro: Forense; São Paulo: MÉTODO, 2018.

CASSAR, Vólia Bonfim. Comentário à medida provisória 936/2020. Rio de Janeiro: Academia Brasileira de Direito do Trabalho. Disponível em: http://www.andt.org.br/f/COMENT\%C3\%81RIOS\%20\%C3\%80\%20MEDIDA\%20PROVIS\%C3\%93RIA \% 20936-20.pdf /. Acesso em 19 de ago. 2020.

CHÃO DE FÁBRICA: Um documentário sobre a história do sindicalismo. Direção de Renato Tapajós e Hidalgo Romero. CUT, 2018, 1:29:00.

CORTELLA, Mário Sérgio: Por que fazemos o que fazemos: aflições vitais sobre o trabalho, carreira e realização. 2. Ed - São Paulo: Planeta, 2017. 
DELGADO, Maurício Godinho: A reforma trabalhista no Brasil : com os comentários à Lei n. 13.467/2017 - São Paulo: LTr, 2017.

FERREIRA, Aline: Transição Do Trabalho Escravo Para O Trabalho Assalariado. Artigo, 2008. Disponível em: https://administradores.com.br/artigos/transicao-do-trabalho-escravo-para-o-trabalho-assalariado. Acesso em 18 de out de 2019.

GUIMARÃES, Deocleciano Torrieri. Dicionário técnico jurídico/ Deocleciano Torrieri Guimarães (in memoriam); atualização de Ana Cláudia Schwenck dos Santos. - 19.ed.- São Paulo: Rideel, 2016.

Instituto de Pesquisa Econômica Aplicada - IPEA. Disponível em: http:/ / www.ipea.gov. br/portal/index.php?option=com_content\&id=29256.Acesso em: 6 de maio 2019.

LEÃO XIII, Papa: RerumNovarum. 1891. Disponível em: http://www.vatican.va/content/leo-xiii/pt/encyclicals/documents/hf_l-xiii_enc_15051891_rerum-novarum.html. Acesso em 23 de fev. de 2019. 38.

NASCIMENTO, Amauri Mascaro. Iniciação ao direito do trabalho. 38. Ed. São Paulo: LTr,2013.

NETO, Alberto Emiliano de Oliveira. Contribuições Sindicais: modalidades de financiamento sindical e o princípio da liberdade sindical - de acordo com a lei n. 13.467/17 (reforma trabalhista). $2^{a}$. ed. LTr. 2019.

MIGUEL,Luis Felipe.Democracia e Representação: territórios em disputa. São Paulo: UNESP,2014. 2014.

MARX, Karl; ENGELS, Friedrich. Manifesto Comunista. São Paulo:Boitempo Editorial), 2005 .

MARX, Karl. A REVOLUÇÃO ANTES DA REVOLUÇÃO - Col. Assim Lutam os Povos Vol. II - Expressão Popular. 2012.

MENDES, Felipe Prata. Os sindicatos no Brasil e o modelo de democracia ampliada. São Paulo: LTr, 2018.

MENDES, Felipe. FGV já detecta alta dramática do desemprego no país. Veja, São Paulo, 07 abr. 2020. Disponível em: https:/ / veja.abril.com.br/economia/fgv-ja-detecta-alta-dramatica-do-desemprego-no-pais/. Acesso em: 16 ago. 2020.

ONU. DECLARAÇÃO UNIVERSÃO DOS DIREITOS HUMANOS. Disponível em: https://www.ohchr.org/EN/UDHR/Pages/Language.aspx?LangID=por. Acesso em: 25 de nov. 2019

PORTO, Lorena Vasconcelos. Medidas provisórias n. 927/2020 e 936/2020: negociação coletiva e controle de convencionalidade. Revista do Tribunal Regional do Trabalho da 3. Região. Belo Horizonte, edição especial, t. I, p. 147-170, jul. 2020.

RIBEIRO,Andressa de Freitas: Taylorismo, fordismo e Toyotismo. Disponível em:https:/ / revistas.pucsp.br/ls/article/view/26678. Acesso em 15 de nov. de 2019. 
SANTOS, Ariane Joice dos. Direito coletivo do trabalho: as relações coletivas de trabalho após o advento da lei da reforma trabalhista (Lei n.13.467/2017). São Paulo: LTr, 2019 SILVA, Homero Batista Mateus da. CLT Comentada / Homero Batista Mateus da Silva. 2. ed. São Paulo:Thomson Reuters Brasil, 2019.

TEMPOS Modernos: Charles Chaplin, EUA, United Artists, 1936. 